\title{
Warming Decreases Bioconversion of Polyunsaturated Fatty Acids in Chironomid Larvae Maintained on Cyanobacterium Microcystis
}

\author{
Ursula Strandberg * ${ }^{\mathbb{D}}$, Timo Ilo, Jarkko Akkanen and Paula Kankaala
}

check for updates

Citation: Strandberg, U.; Ilo, T.; Akkanen, J.; Kankaala, P. Warming Decreases Bioconversion of

Polyunsaturated Fatty Acids in Chironomid Larvae Maintained on Cyanobacterium Microcystis. Biomolecules 2021, 11, 1326. https:// doi.org/10.3390/biom11091326

Academic Editor: Michail I. Gladyshev

Received: 29 July 2021

Accepted: 3 September 2021

Published: 7 September 2021

Publisher's Note: MDPI stays neutral with regard to jurisdictional claims in published maps and institutional affiliations.

Copyright: (c) 2021 by the authors. Licensee MDPI, Basel, Switzerland. This article is an open access article distributed under the terms and conditions of the Creative Commons Attribution (CC BY) license (https:// creativecommons.org/licenses/by/ $4.0 /)$.
Department of Environmental and Biological Sciences, University of Eastern Finland, 80101 Joensuu, Finland; timo.ilo@uef.fi (T.I.); jarkko.akkanen@uef.fi (J.A.); paula.kankaala@uef.fi (P.K.)

* Correspondence: ursula.strandberg@uef.fi

\begin{abstract}
Cyanobacteria dominance and warming have been suggested to decrease the production of polyunsaturated fatty acids (PUFA) in freshwater ecosystems. Physiological adaptations of poikilothermic animals to higher temperatures may further decrease PUFA levels in aquatic food webs. We conducted diet manipulation experiments to investigate the combined effects of dietary PUFA and warming on the proportions of eicosapentaenoic acid (EPA) and arachidonic acid (ARA) in Chironomus riparius. The experimental diet consisted of a nontoxic cyanobacterium Microcystis, which contained $C_{20}$ PUFA: 20:3n-3, 20:4n-3, and 20:3n-6, but no EPA or ARA. Additionally, we used TetraMin ${ }^{\circledR}$ fish flakes as a control treatment. A temperature increase from $20{ }^{\circ} \mathrm{C}$ to $25{ }^{\circ} \mathrm{C}$ decreased the proportion of n-3 $C_{20}$ PUFA and the n-3/n-6 ratio in Microcystis. Diet manipulation experiments indicated that Chironomus desaturated dietary $\mathrm{C}_{20}$ precursors to EPA and ARA, but warming decreased this bioconversion and resulted in lower levels of EPA and ARA in Chironomus. Warming did not alter the proportions of EPA and ARA in Chironomus larvae if these PUFA were readily available in the diet (TetraMin ${ }^{\circledR}$ control treatment). In conclusion, warming and cyanobacteria dominance may decrease the production and trophic transfer of physiologically important PUFA in freshwaters by (1) decreasing the $n-3 / n-6$ ratio and the abundance of $n-3 C_{20}$ precursors in Microcystis, and (2) decreasing the bioconversion of $n-3$ and $n-6 C_{20}$ precursors to EPA and ARA in chironomids. These changes may have cascading effects throughout the food web and decrease the content of EPA in fish, potentially affecting its availability to humans.
\end{abstract}

Keywords: ARA; climate change; Chironomus riparius; desaturation; EPA

\section{Introduction}

Freshwater ecosystems are particularly susceptible to global warming because lake chemistry and hydrology are highly climate-dependent, and aquatic ecosystems are already exposed to numerous anthropological stressors, such as increased loading of nutrients, leading to eutrophication of lakes and rivers [1,2]. Increased algal and cyanobacterial blooms threaten the functioning of aquatic ecosystems, fisheries, and human health $[3,4]$. Increased cyanobacteria dominance and warming have been suggested to decrease the basal production of n-3 and n- 6 polyunsaturated fatty acids ( $n-3$ and n-6 PUFA) [5,6]. The decreased basal production of n-3 and n-6 PUFA is predominantly caused by changes in the phytoplankton community structure because the composition of PUFA in algae and cyanobacteria is phylogenetically determined $[7,8]$. Cyanobacteria do not contain highly unsaturated PUFA, such as arachidonic acid (ARA), eicosapentaenoic acid (EPA), or docosahexaenoic acid (DHA) [9], which are considered physiologically important for most animals. Additionally, laboratory experiments indicated that warming alters the fatty acid composition in algae and cyanobacteria $[10,11]$. In general, the proportion of PUFA and the $n-3 / n-6$ ratio in phytoplankton decrease with increasing temperature $[10,11]$. 
Trophic transfer and trophic upgrading of PUFA are highly important in determining the availability of PUFA to upper trophic level consumers, such as fish. Trophic upgrading refers to mechanisms in which a consumer "improves" the dietary fatty acid composition by (1) selectively retaining important PUFA in their tissues or (2) modifying dietary PUFA to physiologically more active forms, typically via chain elongation and/or desaturation [12,13]. Generally, the abundance of $C_{20}$ and /or $C_{22}$ PUFA increases with each trophic step [14], but exceptions are common. For instance, retroconversion of $C_{22}$ PUFA to $C_{20}$ PUFA has been detected in, for example, cladocerans and chironomids [15,16]. Chironomids (Diptera: Chironomidae) are nonbiting midges whose life cycle includes aquatic egg, larval and pupal stages, and an aerial adult stage [17]. They are opportunistic omnivorous feeders with wide ecological tolerance and a short life cycle, enabling them to thrive in diverse habitats, in both the lentic and lotic environments [18]. Chironomids are a dominant group in freshwater ecosystems, often accounting for more than $50 \%$ of the macroinvertebrate community in lakes [19]. Chironomids are ectotherms; thus, their body temperature reflects that of the environment and ambient temperature drives physiological processes. For instance, the developmental rates increase with ambient temperature until a taxaspecific limit is reached [20-22]. Additionally, the size and fecundity of females have been suggested to decrease at high temperatures [21]. In addition to temperature, the quantity and quality of diet, specifically PUFA availability, have been linked to the developmental rate and growth of chironomids $[23,24]$.

We have previously shown that Chironomus riparius (hereinafter referred to as Chironomus) maintained on cyanobacterium Microcystis have surprisingly high levels of EPA and ARA, considering that these PUFA are not found in Microcystis [16]. Dietary $\mathrm{C}_{18}$ precursors alone could not explain the higher-than-expected ARA and/or EPA levels in Chironomus [16]. We concluded that most likely the $C_{20}$ precursors in Microcystis, i.e., 20:3n6 and 20:4n-3, were $\triangle 5$-desaturated to ARA and EPA, respectively (Figure 1). Theoretically, Chironomus could also express $\Delta 8$-desaturase activity, i.e., desaturation of dietary 20:3n-3, which is also found in Microcystis, to 20:4n-3, after which 20:4n-3 may be $\Delta 5$-desaturated to EPA [25]. The fatty acid modification pathways in invertebrates differ from those of mammals $[25,26]$, and $\Delta 8$-desaturase activity has been suggested in certain teleost fish, molluscs, and annelids $[25,27]$. However, we are not aware of any study showing $\Delta 8$-desaturase activity in chironomids, but this warrants further study, and thus we also considered 20:3n-3 as a potential precursor for EPA.

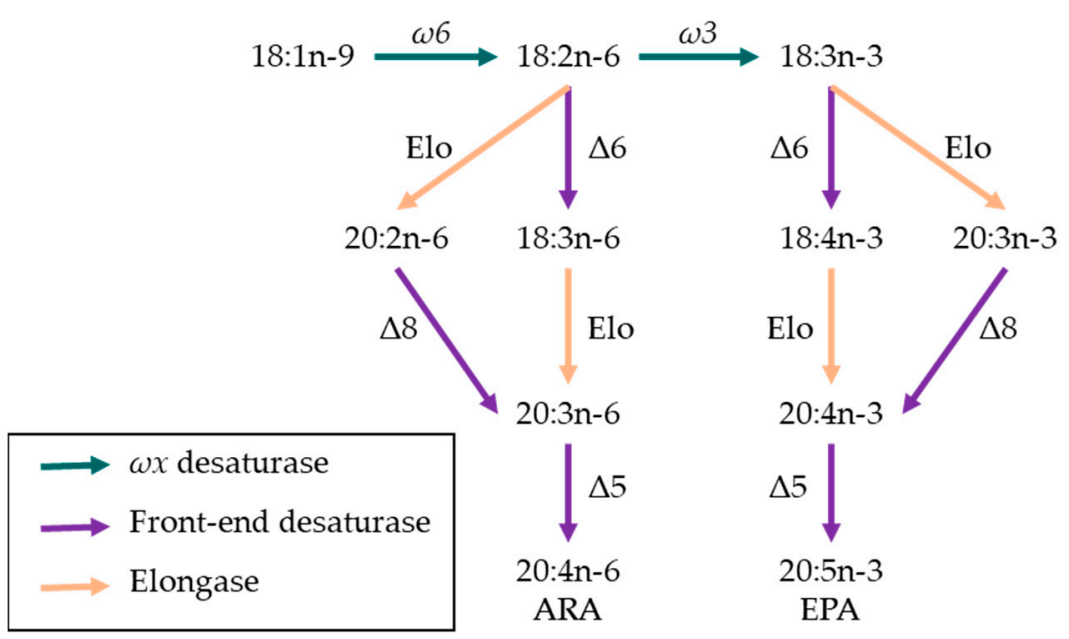

Figure 1. Simplified depiction of potential biosynthetic pathways of polyunsaturated fatty acids discussed in the current study (modified from Monroig and Kabeya 2018). $\Delta x$ and $\omega x$ desaturases refer to the position of the added double bond; position of the added double bond is marked either from the methyl end ( $\omega$ desaturases) or from the carboxyl end ( $\Delta$ desaturases, also called front-end desaturases) of the acyl chain. Elongation reactions are marked with "Elo". 
The aim of this study was to evaluate the effects of $C_{20}$ precursor abundance in the diet and ambient temperature on the proportions of ARA and EPA in Chironomus larvae. We manipulated the cellular fatty acid composition in Microcystis by culturing it at different temperatures, after which Microcystis were fed to Chironomus larvae maintained at $20^{\circ} \mathrm{C}$ and $25{ }^{\circ} \mathrm{C}$. We hypothesized that warming will decrease the proportion of $\mathrm{C}_{20}$ precursors and the n-3/n-6 ratio in Microcystis, as shown in a previous study [11]. We also hypothesized that $A$ ) the abundance of $C_{20}$ precursors in the diet affects the proportions of ARA and EPA in Chironomus larvae, and B) warming decreases the proportion of ARA and EPA in Chironomus larvae maintained on Microcystis because of downregulated $\Delta 5$-desaturase activity at higher temperatures, as shown for a cyclopoid copepod, Paracyclopina nana [28].

\section{Materials and Methods}

We conducted diet manipulation experiments on Chironomus larvae at different temperatures. The experiments were conducted in a temperature-controlled room at $20{ }^{\circ} \mathrm{C}$ and $25^{\circ} \mathrm{C}$. We had four diet treatments: two experimental diets and two controls. The experimental diets consisted of fresh nontoxic cyanobacteria Microcystis, which had been cultured at $20^{\circ} \mathrm{C}$ or $25^{\circ} \mathrm{C}$, hereinafter referred to as Micro20 and Micro25, respectively. The cultures were maintained at these temperatures for at least one month prior to the experiments. In addition to the Microcystis diet treatments, we had a positive control (TetraMin ${ }^{\circledR}$ fish food, Tetrawerke, Melle, Germany) and a negative control (no food). We used natural sediment in the experiments, thus the negative control was included to exclude possible sediment effects on Chironomus fatty acids. The sediment was collected on 4 June 2019 from Lake Höytiäinen (coordinates $62^{\circ} 03.533^{\prime} \mathrm{N}, 26^{\circ} 08.167^{\prime} \mathrm{E}$ ) and sieved through a $1 \mathrm{~mm}$ sieve to remove animals and larger particles and stored at $4{ }^{\circ} \mathrm{C}$. Homogenized sediment was portioned to $400 \mathrm{~mL}$ beakers after which the beakers were filled with artificial freshwater (Ca $+\mathrm{Mg}$ hardness $0.5 \mathrm{mmol}^{-1}, \mathrm{pH}$ 6.6) and left to settle for 2 days. The sediment to water ratio was 1:4.

We used newly hatched (less than $48 \mathrm{~h}$ ) first instar larvae in the experiments. The larvae were obtained from cultures maintained at $\sim 20^{\circ} \mathrm{C}$ at the University of Eastern Finland, Joensuu. Fresh egg clutches were collected and left to hatch in small beakers at the experimental temperatures, i.e., either at $20^{\circ} \mathrm{C}$ or at $25^{\circ} \mathrm{C}$. Temperatures within the range of $15-27^{\circ} \mathrm{C}$ have not been noted to affect the survival of Chironomus riparius larvae [22]. Each treatment had five replicate beakers, and each beaker had 10 larvae. Beakers were continuously aerated. Larvae were fed every other day, and diet was adjusted to $\sim 0.4 \mathrm{mg}$ $C$ larva $^{-1}$ day $^{-1}$. Particles were allowed to set for an hour before continuing with the aeration. The experiments lasted nine days and on the fifth day, about half of the water in the beakers was siphoned and replaced with new artificial freshwater. The experiments were conducted at $20{ }^{\circ} \mathrm{C}$ and $25^{\circ} \mathrm{C}$ with 16:8 $\mathrm{h}$ light:dark cycle. During the experiment, temperature variation was less than $\pm 1{ }^{\circ} \mathrm{C}$, dissolved oxygen saturation was greater than $60 \%$, and ammonium $\left(\mathrm{NH}_{4}{ }^{+}\right)$content did not rise above $18 \mathrm{mg} \mathrm{L}^{-1}$, i.e., $\mathrm{NH}_{4}{ }^{+}$content was below a harmful level $[29,30]$. At the end of the experiment, the $\mathrm{pH}$ in the Micro20 and Micro25 treatments was 6.8-7.1, thus within the OECD guidelines ( $\mathrm{pH} 6-9)$ [29]. In the positive control (TetraMin diet), the $\mathrm{pH}$ was 5.6-6 and in the negative control (no food) 5.5-6. However, we did not observe negative effects on larvae growth or survival in the positive control, and predictably all larvae died in the negative control.

At the end of the experiment, the larvae were sieved from the sediment, counted and stored at $-80{ }^{\circ} \mathrm{C}$. All the individuals were used for the fatty acid analyses and thus we did not measure larval length or estimate the instar. Samples were lyophilized and weighed. The sample dry weight was $0.6-2.6 \mathrm{mg}$. Samples were extracted twice with chloroform: methanol (2:1) [31], and $10 \mu \mathrm{g}$ of free fatty acid 23:0 was added as an internal standard. Extracted lipids were transmethylated at $90{ }^{\circ} \mathrm{C}$ for $90 \mathrm{~min}$. using $1 \%$ sulfuric acid in methanol as a catalyst, see method details in Strandberg et al. [16]. Fatty acid samples were analyzed with an Agilent 6890N gas chromatogram equipped with an Agilent 5973N mass selective detector (Agilent Technologies, Santa Clara, CA, USA). The column was a 
DB-23 (Agilent length $60 \mathrm{~m}$, inner diameter $0.25 \mathrm{~mm}$, film thickness $0.15 \mu \mathrm{m}$ ). We used helium as a carrier gas with an average velocity of $27 \mathrm{~cm} \mathrm{~s}^{-1}$. The initial oven temperature was $50{ }^{\circ} \mathrm{C}$, which was held for $1 \mathrm{~min}$, after which the temperature was raised by $15^{\circ} \mathrm{C}$ $\min ^{-1}$ until $150{ }^{\circ} \mathrm{C}$, and then by $0.5^{\circ} \mathrm{C}$ min $^{-1}$ until the oven temperature was $170{ }^{\circ} \mathrm{C}$, and finally by $2{ }^{\circ} \mathrm{C} \min ^{-1}$ until the final temperature of $230{ }^{\circ} \mathrm{C}$ was reached. We used mass spectra and reference standard GLC-538 (Nu-check prep.) for peak identification. GLC-538 was also used as a calibration standard for the quantification of fatty acids. Fatty acids were presented as weight \% of total fatty acids. Total fatty acids were presented as micrograms of fatty acid per milligram dry weight $\left(\mu \mathrm{g} \mathrm{mg}{ }^{-1} \mathrm{DW}\right)$. Larval weights were presented as $\mathrm{mg} \mathrm{DW}^{-1}$.

We used two-way ANOVA to test the differences in the fatty acid response variables (EPA w\% or ARA w\%), total fatty acid content and dry weight in Chironomus larvae, using 'Diet' and 'Temperature' as independent variables. 'Diet' included three levels: Micro20, Micro25, and TetraMin ${ }^{\circledR}$ and 'Temperature' two levels: $20{ }^{\circ} \mathrm{C}$ and $25^{\circ} \mathrm{C}$. We used 0.05 as the alpha level and Type III sum of squares. We used Levene's test to investigate the homogeneity of variances in the data. Larval dry weight, total FA content, and ARA w\% had equal variances. The EPA $\mathrm{w} \%$ was the arcsine square root transformed to achieve equal variances. Statistical analyses were performed with IBM SPSS Statistics 27.

\section{Results}

The Microcystis diet contained $\mathrm{C}_{20}$ precursors but not EPA or ARA, while the TetraMin ${ }^{\circledR}$ control diet contained EPA and ARA (Table 1). The culture temperature altered the fatty acid profile of Microcystis. The proportion of 20:3n-6, which is a $C_{20}$ precursor fatty acid for ARA, increased from about $0.35 \mathrm{w} \%$ in Micro20 to $0.71 \mathrm{w} \%$ in Micro25. The proportion of 20:3n-3 and 20:4n-3, potential $C_{20}$ precursor fatty acids for EPA, declined from $0.84 \mathrm{w} \%$ to $0.19 \mathrm{w} \%$ and from $1.93 \mathrm{w} \%$ to $0.21 \mathrm{w} \%$, respectively, when Microcystis was cultured at the higher temperature. Moreover, the proportion of $n-6 C_{18}$ PUFA increased and n- $3 C_{18}$ PUFA decreased in Microcystis at the higher temperature (Table 1). Overall, warming decreased the proportion of n-3 PUFA and increased the proportion of n-6 PUFA in Microcystis (Table 1). Consequently, the $n-3 / n-6$ ratio in Microcystis declined from 2.48 to 0.47 as the culture temperature increased from $20^{\circ} \mathrm{C}$ to $25^{\circ} \mathrm{C}$. Subsequently, the Micro20 diet can be characterized as a higher quality diet than Micro25, in terms of the abundance of n-3 $C_{20}$ precursors and the $n-3 / n-6$ ratio.

\subsection{EPA and ARA in Chironomus}

Diet and temperature significantly affected the proportions of EPA and ARA in Chironomus (Table 2 ). Diet could explain $\sim 83 \%$ of the variation in EPA $\mathrm{w} \%$ and $~ 81 \%$ of the variation in ARA w\% (Table 2). Temperature could explain $\sim 2 \%$ of the variation in EPA $\mathrm{w} \%$ (Table 2 ) and $\sim 7 \%$ of the variation in ARA w\% (Table 2 ). The highest proportion of EPA was found in Chironomus fed with TetraMin ${ }^{\circledR}$, regardless of the experimental temperature (Figure 2A). In contrast, the proportions of ARA were lower in Chironomus fed with TetraMin ${ }^{\circledR}$ than in Chironomus fed with either Micro20 or Micro25, but the ARA levels did not differ between Micro20 and Micro25 diets. Warming did not affect the EPA w\% and ARA w\% in Chironomus fed with TetraMin ${ }^{\circledR}$ but decreased the proportions of EPA and ARA in Chironomus fed with Microcystis (ESM Tables S1 and S2). In Micro20 and Micro25 diet treatments, warming significantly decreased the proportion of ARA in Chironomus larvae from about 7.2-7.8 $\mathrm{w} \%$ to $5.2-5.8 \mathrm{w} \%$ when the experimental temperature increased from $20{ }^{\circ} \mathrm{C}$ to $25^{\circ} \mathrm{C}$ (ESM Table S1). In the Micro20 treatment, the EPA w\% in Chironomus declined from $4.0 \mathrm{w} \%$ to $3.5 \mathrm{w} \%$, but the decline was not statistically significant $(p=0.098$, ESM Table S2), whereas in the Micro25 treatment the temperature-induced decline in EPA from $3.2 \mathrm{w} \%$ to $2.3 \mathrm{w} \%$ in Chironomus was statistically significant (ESM Table S2). 
Table 1. Major fatty acids and sum of $n-3$ and $n-6$ PUFA expressed as $w \%$ of total fatty acids, and the n-3/n-6 ratio in diets: Micro20, Micro25, and TetraMin ${ }^{\circledR}$ fish flakes (number of samples $n=3$ for all diets). The presented fatty acids accounted for more than $99 \%$ of all fatty acids in Microcystis diets (Micro20 and Micro25), and more than $92 \%$ of all fatty acid in TetraMin ${ }^{\circledR}$. The lower percentage in TetraMin ${ }^{\circledR}$ is due to the exclusion of long-chain saturated ( $\geq C_{20}$ LC-SFA) and monounsaturated fatty acids ( $\geq \mathrm{C}_{20}$ LC-MUFA) from the table, which are prevalent in TetraMin ${ }^{\circledR}$ but not in Microcystis, see also Strandberg et al. [16].

\begin{tabular}{ccccccc}
\hline \multirow{2}{*}{ Fatty Acid } & \multicolumn{2}{c}{ Micro20 } & \multicolumn{2}{c}{ Micro25 } & \multicolumn{2}{c}{ TetraMin ${ }^{\circledR}$} \\
\cline { 2 - 6 } & Mean & SD & Mean & SD & Mean & SD \\
\hline $14: 0$ & 0.40 & 0.10 & 0.56 & 0.16 & 2.82 & 0.00 \\
i15:0 & 0.28 & 0.06 & 0.87 & 0.23 & 0.05 & 0.00 \\
$15: 0$ & 0.08 & 0.03 & 0.29 & 0.08 & 0.21 & 0.01 \\
$16: 0$ & 44.19 & 1.40 & 46.23 & 3.93 & 15.08 & 0.40 \\
$16: 1 \mathrm{n}-9$ & 0.47 & 0.02 & 0.24 & 0.06 & 0.08 & 0.01 \\
$16: 1 \mathrm{n}-7$ & 1.40 & 0.13 & 1.64 & 0.09 & 2.63 & 0.01 \\
$18: 0$ & 4.25 & 1.86 & 6.38 & 3.31 & 11.75 & 0.17 \\
$18: 1 \mathrm{n}-9$ & 1.20 & 0.13 & 1.92 & 0.39 & 24.86 & 0.25 \\
$18: 1 \mathrm{n}-7$ & 3.00 & 0.80 & 5.55 & 0.70 & 2.40 & 0.04 \\
$18: 2 \mathrm{n}-6$ & 3.04 & 0.13 & 6.79 & 0.31 & 22.52 & 0.19 \\
$18: 3 \mathrm{n}-6$ & 9.40 & 0.35 & 16.95 & 1.13 & 0.01 & 0.00 \\
$18: 3 \mathrm{n}-3$ & 10.87 & 0.44 & 5.02 & 0.92 & 3.46 & 0.09 \\
$18: 4 \mathrm{n}-3$ & 18.04 & 1.02 & 6.05 & 1.15 & 0.34 & 0.02 \\
20:2n-6 & 0.00 & 0.00 & 0.00 & 0.00 & 0.19 & 0.03 \\
$20: 3 \mathrm{n}-6$ & 0.35 & 0.20 & 0.71 & 0.69 & 0.01 & 0.00 \\
20:4n-6 & 0.00 & 0.00 & 0.00 & 0.00 & 0.14 & 0.02 \\
20:3n-3 & 0.84 & 0.37 & 0.19 & 0.17 & 0.02 & 0.02 \\
20:4n-3 & 1.93 & 0.50 & 0.21 & 0.16 & 0.09 & 0.02 \\
20:5n-3 & 0.00 & 0.00 & 0.00 & 0.00 & 2.82 & 0.15 \\
22:5n-3 & 0.00 & 0.00 & 0.00 & 0.00 & 0.32 & 0.03 \\
$22: 6 \mathrm{n}-3$ & 0.00 & 0.00 & 0.00 & 0.00 & 2.92 & 0.16 \\
Sum n-6 PUFA & 12.79 & 0.18 & 24.45 & 0.19 & 22.87 & 0.15 \\
Sum n-3 PUFA & 31.69 & 0.61 & 11.47 & 2.11 & 9.96 & 0.13 \\
n-3/n-6 & 2.48 & 0.05 & 0.47 & 0.08 & 0.44 & 0.01 \\
\hline
\end{tabular}

Table 2. Two-way ANOVA summary table for EPA w\% and ARA w\% in Chironomus riparius across diet and temperature treatments.

\begin{tabular}{|c|c|c|c|c|c|c|c|}
\hline Variable & Source & df & SS & MS & $\mathbf{F}$ & $p$ & $\begin{array}{c}\text { Effect Size } \\
\text { (Eta Squared) }\end{array}$ \\
\hline \multirow[t]{5}{*}{ EPA $w \%$} & Diet & 2 & 44.218 & 22.109 & 91.176 & $<0.001$ & 0.829 \\
\hline & Temperature & 1 & 1.148 & 1.148 & 4.733 & 0.040 & 0.022 \\
\hline & Diet $\times$ Temperature interaction & 2 & 1.529 & 0.764 & 3.152 & 0.062 & 0.029 \\
\hline & Within group & 23 & 5.577 & 0.242 & & & \\
\hline & Total & 28 & 53.367 & & & & \\
\hline \multirow[t]{5}{*}{ ARA $w \%$} & Diet & 2 & 155.027 & 77.513 & 120.595 & $<0.001$ & 0.810 \\
\hline & Temperature & 1 & 12.715 & 12.715 & 19.782 & $<0.001$ & 0.066 \\
\hline & Diet $\times$ Temperature interaction & 2 & 6.598 & 3.299 & 5.132 & 0.014 & 0.034 \\
\hline & Within group & 23 & 14.783 & 0.643 & & & \\
\hline & Total & 28 & 191.348 & & & & \\
\hline
\end{tabular}




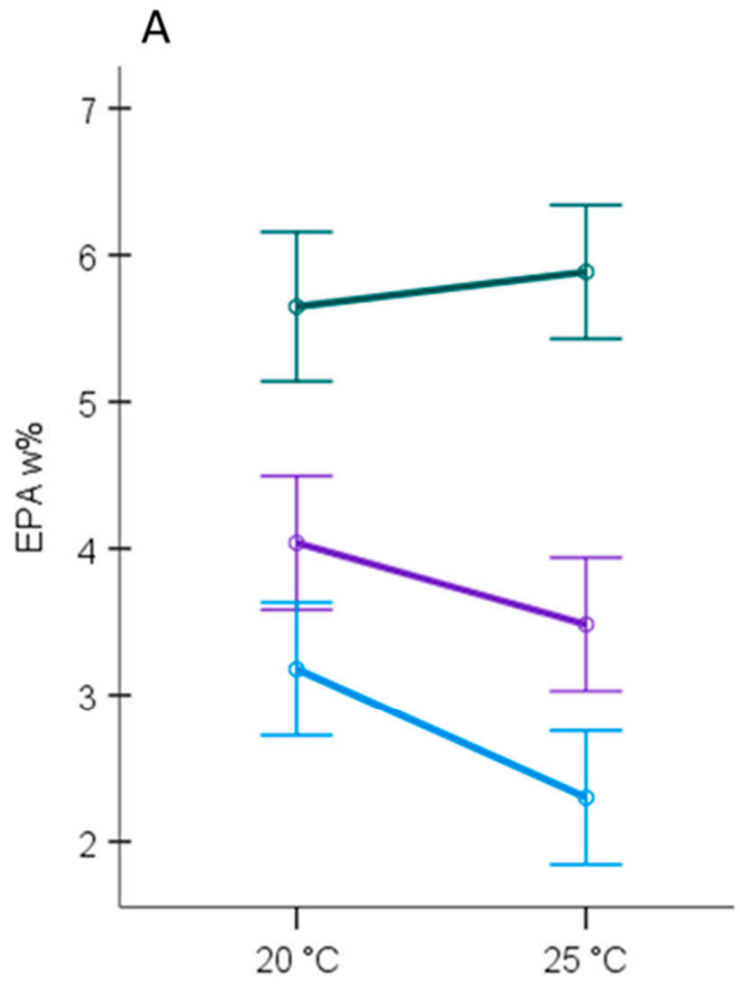

Experimental temperature

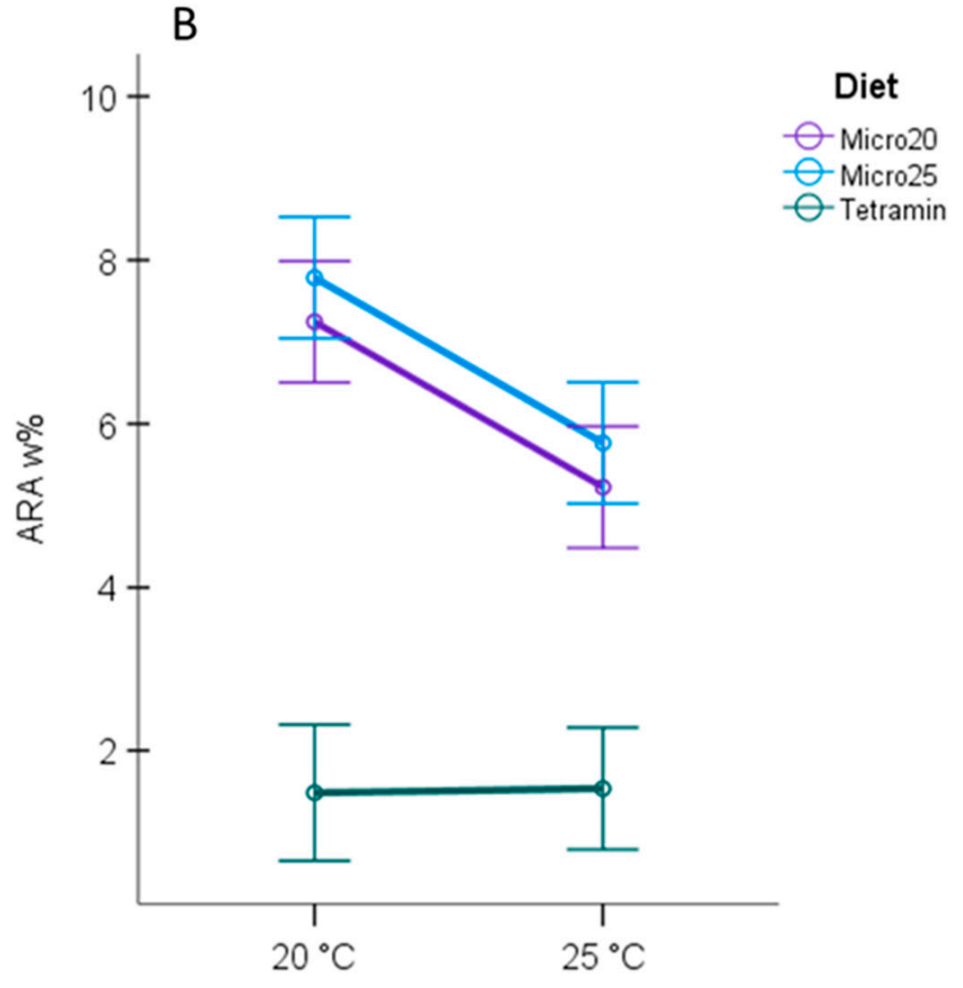

Experimental temperature

Figure 2. Estimated marginal means for (A) EPA w\% and (B) ARA w\% in Chironomus fed with either Micro20, Micro25, or TetraMin ${ }^{\circledR}$ (control) and maintained at two different experimental temperatures: $20{ }^{\circ} \mathrm{C}$ and $25{ }^{\circ} \mathrm{C}$. Error bars represent $95 \%$ confidence intervals. The mean EPA w\% values differed between the Microcystis diet treatments (Micro20 and Micro25). The mean EPA $w \%$ decreased with increasing temperature in both diet treatments, but the decrease was statistically significant only for the Micro25 diet. The mean ARA w\% in Chironomus did not differ between Micro20 and Micro25 diets, and the temperature significantly deceased ARA $w \%$ in both diet treatments. Temperature did not affect the EPA $w \%$ and ARA $w \%$ in Chironomus fed with TetraMin ${ }^{\circledR}$.

\subsection{Total Fatty Acid Content and Dry Weight}

The total fatty acid content and dry weight in Chironomus were the highest in larvae fed with TetraMin ${ }^{\circledR}$ (Figure 3A,B). Warming significantly decreased the total fatty acid content from 75.9 to $45.8 \mu \mathrm{g} \mathrm{mg}^{-1} \mathrm{DW}$ when larvae were fed with TetraMin ${ }^{\circledR}$. The total fatty acid content in Chironomus decreased also in the Microcystis diet treatments (Figure 3A, ESM Table S3), but the decline was not as large as for the TetraMin ${ }^{\circledR}$ diet. The larval dry weight (mg ind ${ }^{-1}$ ) did not respond to increasing temperature in Chironomus fed with TetraMin ${ }^{\circledR}$ but increased in Chironomus fed with Microcystis, albeit the increase was statistically significant only for the Micro20 diet (Figure 3B, ESM Table S4). 


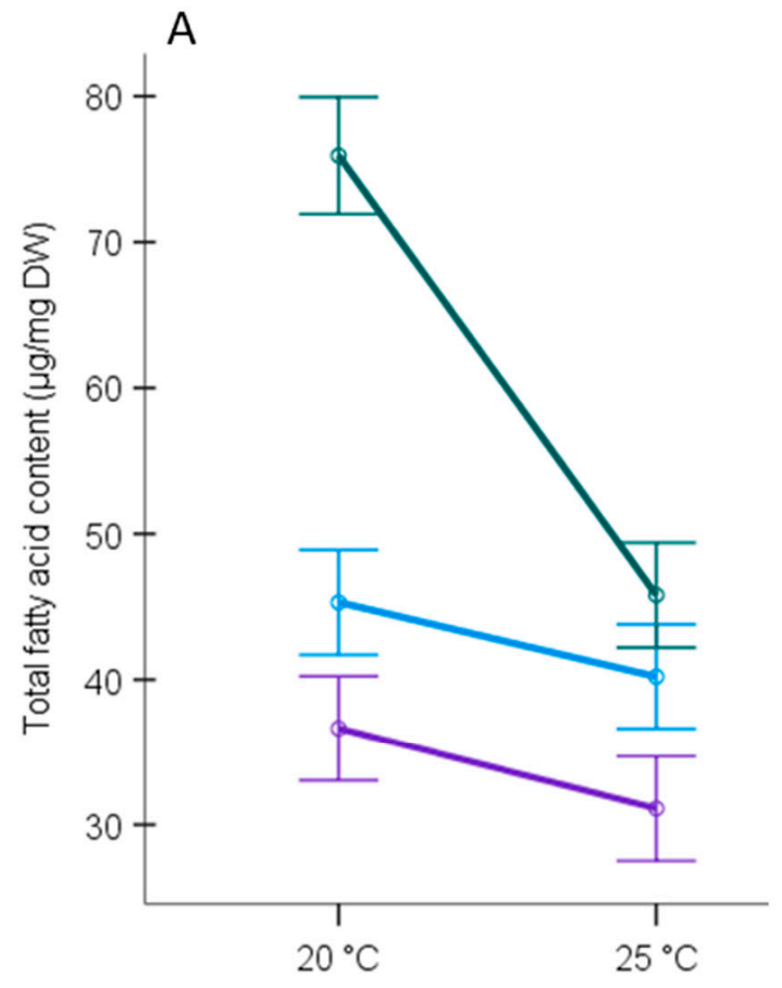

Experimental temperature

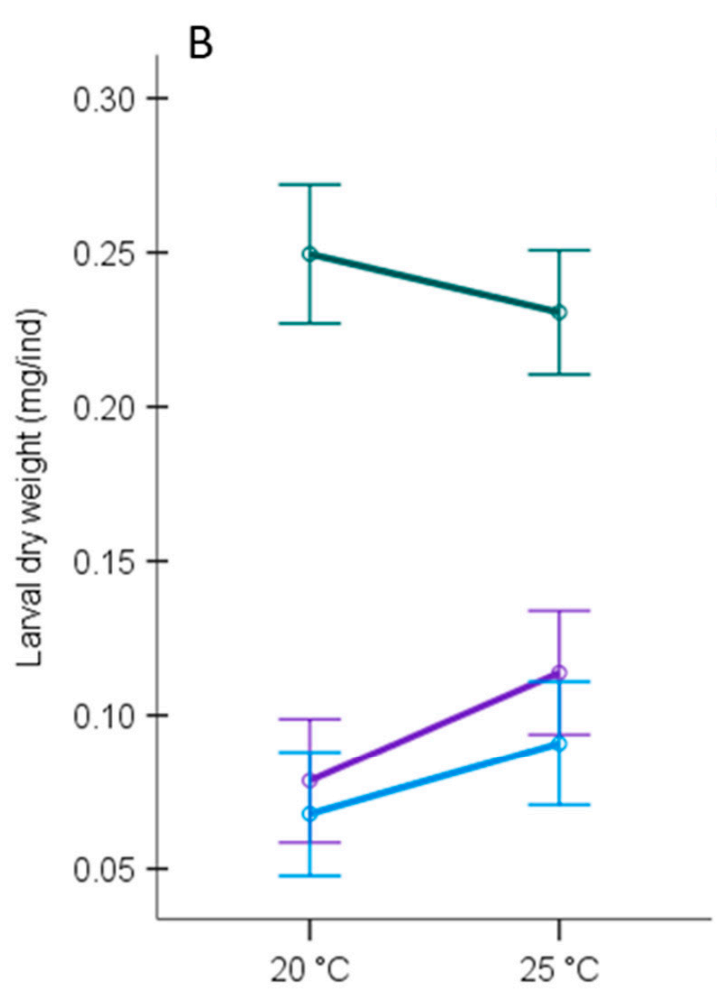

Experimental temperature

Figure 3. Estimated marginal means for (A) Total fatty acid content $\left(\mu \mathrm{g} \mathrm{mg}^{-1}\right)$ in Chironomus larvae, and (B) Larval dry weight $\left(\mathrm{mg}\right.$ ind $\left.{ }^{-1}\right)$. Error bars represent $95 \%$ confidence intervals. Warming significantly decreased the larval total fatty acid content in the Microcystis treatments and in the TetraMin ${ }^{\circledR}$ control $(p<0.05)$. Warming increased the larval dry weight in the Microcystis treatment, albeit the increase was statistically significant only for Micro20 diet. Warming did not affect larval dry weight in the TetraMin ${ }^{\circledR}$ control.

\section{Discussion}

Our results indicated that Chironomus desaturated cyanobacterial n-3 and n- $6 C_{20}$ PUFA to physiologically more active forms, i.e., EPA and ARA. This trophic upgrading is ecologically relevant because Chironomus are abundant and widespread taxa [18]. The trophic upgrading was dependent on both the abundance of precursors in the diet as well as ambient temperature. Warming decreased the proportions of EPA and ARA in Chironomus fed with Microcystis indicating decreased bioconversion of $C_{20}$ precursors to EPA and ARA at higher temperatures. This conclusion is supported by the finding that warming did not affect EPA and ARA levels in Chironomus fed with TetraMin ${ }^{\circledR}$, which contains EPA and ARA. The proportions of EPA and ARA or their $\mathrm{C}_{20}$ precursors in the diet corresponded with the levels of EPA and ARA in Chironomus. These results indicate that warming will decrease trophic upgrading of $C_{20}$ precursors but may not significantly affect the direct trophic transfer of algal EPA and ARA.

Compared to vertebrates, knowledge on the enzymes linked to fatty acid desaturation and elongation processes in invertebrates is still fragmented. Kabeya et al. [32] showed that, contrary to vertebrates, many invertebrates possess the genetic code for the de novo synthesis of n-3 and n-6 PUFA, although it is yet to be determined how efficiently these genes are expressed and which factors control the gene expression. Detailed information on desaturase activities in chironomids is incomplete but most likely it includes the traditional ' $\Delta 6$ desaturation-elongation $-\Delta 5$ desaturation' pathway of $18: 3 n-3$ and 18:2n-6 to EPA or ARA, respectively (Figure 1) $[25,26]$. Results from our previous study indicated that Chironomus efficiently $\Delta 5$-desaturate dietary $C_{20}$ precursors 20:4n-3 and 20:3n-6 to EPA and ARA, respectively [16]. Results from the current study suggest that the $\Delta 5$-desaturation 
of dietary $\mathrm{C}_{20}$ precursors in Chironomus is downregulated at higher temperatures. This conclusion is supported by the absence of warming-induced decrease of EPA $\mathrm{w} \%$ and ARA w\% in Chironomus when these fatty acids were directly available in the diet, i.e., TetraMin ${ }^{\circledR}$ diet. Note that warming decreased ARA w\% in both Microcystis diets even if the proportion of 20:3n-6 increased in the Micro25 diet, suggesting that increased dietary availability of 20:3n- 6 did not compensate for the decreased $\Delta 5$-desaturation activity. Decreased $\Delta 5$-desaturation activity at higher temperatures has been previously documented for crustaceans [28]. Theoretically, also 20:3n-3 may serve as a precursor for EPA if Chironomus expresses $\Delta 8$-desaturase activity: $\Delta 8$-desaturation of dietary 20:3n-3 to $20: 4 n-3$ and subsequent $\Delta 5$-desaturation of 20:4n-3 to EPA (Figure 1) [25]. To our knowledge $\Delta 8$ desaturase activity has not been confirmed in chironomids, even if this metabolic pathway is theoretically possible and also confirmed in certain teleost fish and molluscs [25,27].

Warming significantly altered the PUFA composition in Microcystis, specifically, the n-3/n6 ratio and the proportion of $n-3 C_{20}$ precursors decreased. The warming-induced decrease in the n-3/n-6 ratio in Microcystis is in accordance with previous studies on temperature effects on the fatty acid composition in cyanobacteria and algae $[10,11]$. The decrease in the $n-3 / n-6$ ratio is most likely due to downregulated $\omega 3$ desaturase expression at higher temperatures as noted before for the cyanobacterium Synechocystis sp. (Figure 1) [33]. The $\omega 6$ desaturase was also downregulated at higher temperatures, albeit not as much as $\omega 3$ desaturase [33]. Thus, differing responses of $\omega 3$ and $\omega 6$ desaturase activities to increasing temperature may explain the decline in the n-3/n-6 ratio in Microcystis. Low n-3/n-6 ratio and decreased proportion of n-3 $C_{20}$ precursors in Microcystis likely reduce membrane lipid damage and help to maintain the function of the photosystem II complex and the electron transport system at higher temperatures $[11,34]$.

Global climate change is predicted to increase surface water temperatures in summer and strengthen the thermal stratification in lakes [35], which in turn have been noted to increase the frequency, intensity, and duration of cyanobacteria blooms [36]. In general, cyanobacteria have a lower n-3/n-6 ratio than eukaryotic algae and most cyanobacteria genera do not produce $C_{20}$ PUFA, thus cyanobacteria blooms have been suggested to decrease the basal production of physiologically important PUFA, such as EPA [6]. Microcystis is one of the most common bloom-forming cyanobacteria [4], and the desaturation of $C_{20}$ precursors in Chironomus may indicate a higher-than-expected availability of EPA and ARA to upper trophic level consumers in lakes exposed to nontoxic Microcystis blooms. However, warming may counteract this phenomenon by decreasing the proportion of n-3 $\mathrm{C}_{20}$ precursors in Microcystis and downregulating the bioconversion of both n-3 and n-6 $\mathrm{C}_{20}$ precursors in Chironomus, thus reducing the overall trophic transfer of EPA and ARA in freshwater food webs.

Climate-induced increase in cyanobacteria biomass and the direct temperature effects on the cyanobacterial fatty acids together with the decreased trophic upgrading of $C_{20}$ precursors in chironomids may have cascading effects throughout the food web. The estimated decrease in algal production of EPA and DHA, due to cyanobacteria dominance, correlated with lower levels of EPA and DHA in fish [6]. Chironomus contains only trace amounts of DHA even if abundant in the diet $[16,24]$. Thus, it is highly unlikely that chironomids are important vectors for the trophic transfer of DHA. However, because chironomids are widespread and abundant taxa, they may be highly important for the trophic transfer of EPA in the littoral zone as well as in the pelagic. Chironomid pupae have been noted to be important prey for pelagic fish, thus coupling benthic and pelagic food webs [37]. Additionally, the aerial adult stages serve as vectors for the transfer of EPA from the aquatic environment to the terrestrial consumers, e.g., to insectivore birds and terrestrial spiders $[38,39]$.

The significantly higher larval weights in the TetraMin ${ }^{\circledR}$ control treatment indicate that the Microcystis diet was suboptimal for growth. Warming significantly increased larval weight only in the Micro20 treatment, although an increasing trend was observed also for the Micro25 treatment. We do not have data on larval length or developmental stages, 
which have been previously shown to respond to temperature change [20-22]. Interestingly, warming significantly decreased the total FA content in the TetraMin ${ }^{\circledR}$ treatment even if we did not observe any effect on the dry weight. Females have higher lipid reserves than males [40]. We did not determine the sex of larvae, but it is unlikely that sex ratios would be systematically biased only in this one treatment. Decreased fatty acid content at higher temperatures was observed also for the Microcystis treatments, but the decline was not as large. Lower fat reserves at higher temperatures may be linked with increased physical activity, respiration, and/or different developmental phases as fatty acids are oxidised for energy during molting and chitin synthesis [40].

\section{Conclusions}

The proportions of EPA and ARA in Chironomus were strongly dependent on the dietary availability of these PUFA or their $\mathrm{C}_{20}$ precursors. Warming decreased the proportion of n-3 $C_{20}$ precursors and n-3/n-6 ratio in Microcystis. Additionally, warming decreased the desaturation of $\mathrm{C}_{20}$ precursors, resulting in lower levels of EPA and ARA in Chironomus fed with Microcystis. However, warming did not affect the proportions of EPA and ARA in Chironomus if these PUFA were directly available in the diet (TetraMin ${ }^{\circledR}$ fish flakes). These findings indicate that in chironomids the remodeling of PUFA at higher temperatures may occur via downregulated desaturase activity. Furthermore, our results indicate that global warming and eutrophication of lakes and rivers may decrease the $n-3 / n-6$ ratio at the base of the food web as well as the trophic transfer of EPA and ARA to secondary consumers.

Supplementary Materials: The following are available online at https: / www.mdpi.com/article/ 10.3390/biom11091326/s1, Table S1: Pairwise comparisons of ARA w\% in Chironomus, Table S2: Pairwise comparisons of arcsine square root transformed EPA w\% in Chironomus, Table S3: Pairwise comparisons of total fatty acid content $\left(\mu \mathrm{g} \mathrm{mg}^{-1}\right)$ in Chironomus, Table S4: Pairwise comparisons of the dry weight ( $\mathrm{mg}^{-1}$ ) in Chironomus.

Author Contributions: Conceptualization, U.S. and P.K.; methodology, U.S., T.I. and J.A.; investigation, U.S. and T.I.; writing — original draft preparation, U.S.; writing—review and editing, U.S.; P.K., T.I., J.A.; visualization, U.S.; funding acquisition, P.K. and J.A. All authors have read and agreed to the published version of the manuscript.

Funding: This research was funded by Academy of Finland (research grant \# 310450 to P.K.) and Kone Foundation (grant \# 201710215 to J.A. and T.I.).

Institutional Review Board Statement: Not applicable.

Informed Consent Statement: Not applicable.

Data Availability Statement: Data are available from the authors upon reasonable request.

Acknowledgments: We would like to thank Jiri Vihavainen for his help in the experiments.

Conflicts of Interest: The authors declare no conflict of interest. The funders had no role in the design of the study; in the collection, analyses, or interpretation of data; in the writing of the manuscript, or in the decision to publish the results.

\section{References}

1. Adrian, R.; O’Reilly, C.M.; Zagarese, H.; Baines, S.B.; Hessen, D.O.; Keller, W.; Livingstone, D.M.; Sommaruga, R.; Straile, D.; Van Donk, E.; et al. Lakes as sentinels of climate change. Limnol. Oceanogr. 2009, 54, 2283-2297. [CrossRef]

2. Woodward, G.; Perkins, D.M.; Brown, L.E. Climate change and freshwater ecosystems: Impacts across multiple levels of organization. Philos. Trans. R. Soc. B Biol. Sci. 2010, 365, 2093-2106. [CrossRef] [PubMed]

3. Paerl, H.W.; Huisman, J. Climate change: A catalyst for global expansion of harmful cyanobacterial blooms. Environ. Microbiol. Rep. 2009, 1, 27-37. [CrossRef] [PubMed]

4. Huisman, J.; Codd, G.A.; Paerl, H.W.; Ibelings, B.W.; Verspagen, J.M.H.; Visser, P.M. Cyanobacterial blooms. Nat. Rev. Microbiol. 2018, 16, 471-483. [CrossRef]

5. Hixson, S.M.; Arts, M.T. Climate warming is predicted to reduce omega-3, long-chain, polyunsaturated fatty acid production in phytoplankton. Glob. Chang. Biol. 2016, 22, 2744-2755. [CrossRef] 
6. Taipale, S.J.; Vuorio, K.; Strandberg, U.; Kahilainen, K.K.; Järvinen, M.; Hiltunen, M.; Peltomaa, E.; Kankaala, P. Lake eutrophication and brownification downgrade availability and transfer of essential fatty acids for human consumption. Environ. Int. 2016, 96, 156-166. [CrossRef] [PubMed]

7. Taipale, S.; Strandberg, U.; Peltomaa, E.; Galloway, A.W.E.; Ojala, A.; Brett, M.T. Fatty acid composition as biomarkers of freshwater microalgae: Analysis of 37 strains of microalgae in 22 genera and in seven classes. Aquat. Microb. Ecol. 2013, 71, 165-178. [CrossRef]

8. Galloway, A.W.E.; Winder, M. Partitioning the relative importance of phylogeny and environmental conditions on phytoplankton fatty acids. PLoS ONE 2015, 10, e0130053. [CrossRef] [PubMed]

9. Strandberg, U.; Taipale, S.J.; Hiltunen, M.; Galloway, A.W.E.; Brett, M.T.; Kankaala, P. Inferring phytoplankton community composition with a fatty acid mixing model. Ecosphere 2015, 6, 16. [CrossRef]

10. Renaud, S.M.; Thinh, L.-V.; Lambrinidis, G.; Parry, D.L. Effect of temperature on growth, chemical composition and fatty acid composition of tropical Australian microalgae grown in batch cultures. Aquaculture 2002, 211, 195-214. [CrossRef]

11. De la Rosa, F.; De Troch, M.; Malanga, G.; Hernando, M. Differential sensitivity of fatty acids and lipid damage in Microcystis aeruginosa (cyanobacteria) exposed to increased temperature. Comp. Biochem. Physiol. Part C Toxicol. Pharmacol. 2020, $235,108773$. [CrossRef]

12. Bec, A.; Martin-Creuzburg, D.; von Elert, E. Trophic upgrading of autotrophic picoplakton by heterotrophic nanoflagellate Paraphysomonas sp. Limnol. Oceanogr. 2006, 51, 1699-1707. [CrossRef]

13. Hiltunen, M.; Honkanen, M.; Taipale, S.; Strandberg, U.; Kankaala, P. Trophic upgrading via the microbial food web may link terrestrial dissolved organic matter to Daphnia. J. Plankton Res. 2017, 39, 861-869. [CrossRef]

14. Strandberg, U.; Hiltunen, M.; Jelkänen, E.; Taipale, S.J.; Kainz, M.J.; Brett, M.T.; Kankaala, P. Selective transfer of polyunsaturated fatty acids from phytoplankton to planktivorous fish in large boreal lakes. Sci. Total Environ. 2015, 536, 858-865. [CrossRef] [PubMed]

15. Strandberg, U.; Taipale, S.J.; Kainz, M.J.; Brett, M.T. Retroconversion of docosapentaenoic acid (n-6): An alternative pathway for biosynthesis of arachidonic acid. Lipids 2014, 49, 591-595. [CrossRef] [PubMed]

16. Strandberg, U.; Vesterinen, J.; Ilo, T.; Akkanen, J.; Melanen, M.; Kankaala, P. Fatty acid metabolism and modifications in Chironomus riparius. Philos. Trans. R. Soc. B 2020, 375, 20190643. [CrossRef] [PubMed]

17. Oliver, D.R. Life history of the Chironomidae. Annu. Rev. Entomol. 1971, 16, 211-230. [CrossRef]

18. Pinder, L.C.V. Biology of freshwater Chironomidae. Annu. Rev. Entomol. 1986, 31, 1-23. [CrossRef]

19. Wetzel, R.G. Limnology: Lake and River Ecosystems, 3rd ed.; Academic Press: San Diego, CA, USA, 2001.

20. Sankarperumal, G.; Pandian, T.J. Effects of temperature and Chlorella density on growth and metamorphosis of Chironomus circumdatus (Kieffer) (Diptera). Aquat. Insects 1991, 13, 167-177. [CrossRef]

21. Frouz, J.; Ali, A.; Lobinske, R.J. Influence of temperature on developmental rate, wing length, and larval head capsule size of pestiferous midge Chironomus crassicaudatus (Diptera: Chironomidae). J. Econ. Entomol. 2002, 95, 699-705. [CrossRef] [PubMed]

22. Péry, A.R.R.; Garric, J. Modelling effects of temperature and feeding level on the life cycle of the midge Chironomus riparius: An energy-based modelling approach. Hydrobiologia 2006, 553, 59-66. [CrossRef]

23. Péry, A.R.R.; Mons, R.; Flammarion, P.; Lagadic, L.; Garric, J. A modelling approach to link food availability, growth, emergence, and reproduction for midge Chironomus riparius. Environ. Toxicol. Chem. Int. J. 2002, 21, 2507-2513. [CrossRef]

24. Goedkoop, W.; Demant, M.; Ahlgren, G. Interactions between food quantity and quality (long-chain polyunsaturated fatty acid concentrations) effects on growth and development of Chironomus riparius. Can. J. Fish. Aquat. Sci. 2007, 64, 425-436. [CrossRef]

25. Monroig, Ó.; Kabeya, N. Desaturases and elongases involved in polyunsaturated fatty acid biosynthesis in aquatic invertebrates: A comprehensive review. Fish. Sci. 2018, 84, 911-928. [CrossRef]

26. Leonard, A.E.; Pereira, S.L.; Sprecher, H.; Huang, Y.-S. Elongation of long-chain fatty acids. Prog. Lipid Res. 2004, 43, 36-54. [CrossRef]

27. Liu, H.; Zhang, H.; Zheng, H.; Wang, S.; Guo, Z.; Zhang, G. PUFA biosynthesis pathway in marine scallop Chlamys nobilis Reeve. J. Agric. Food Chem. 2014, 62, 12384-12391. [CrossRef]

28. Lee, S.-H.; Lee, M.-C.; Puthumana, J.; Park, J.C.; Kang, S.; Han, J.; Shin, K.-H.; Park, H.G.; Om, A.-S.; Lee, J.-S. Effects of temperature on growth and fatty acid synthesis in the cyclopoid copepod Paracyclopina nana. Fish. Sci. 2017, 83, 725-734. [CrossRef]

29. OECD. TG 218 Guidelines for Testing Chemicals: Sediment-Water Chironomid Toxicity Test Using Spiked Sediments; OECD Publishing: Paris, France, 2004.

30. Egeler, P.; Henry, K.S.; Riedhammer, H.C. Potential effects of food addition to sediment on test conditions in sediment toxicity test. J. Soils Sediments 2010, 10,377-388. [CrossRef]

31. Folch, J.; Lees, M.; Sloane Stanley, G.H. A simple method for the isolation and purification of total lipids from animal tissues. $J$ Biol. Chem. 1957, 226, 497-509. [CrossRef]

32. Kabeya, N.; Fonseca, M.M.; Ferrier, D.E.K.; Navarro, J.C.; Bay, L.K.; Francis, D.S.; Tocher, D.R.; Castro, L.F.; Monroig, Ó. Genes for de novo biosynthesis of omega-3 polyunsaturated fatty acids are widespread in animals. Sci. Adv. 2018, 4, eaar6849. [CrossRef]

33. Los, D.A.; Ray, M.K.; Murata, N. Differences in the control of the temperature-dependent expression of four genes for desaturases in Synechocystis sp. PCC 6803. Mol. Microbiol. 1997, 25, 1167-1175. [CrossRef] [PubMed] 
34. Wada, H.; Murata, N. Temperature-induced changes in the fatty acid composition of the cyanobacterium, Synechocystis PCC6803. Plant Physiol. 1990, 92, 1062-1069. [CrossRef] [PubMed]

35. Boehrer, B.; Schultze, M. Stratification of lakes. Rev. Geophys. 2008, 46, RG2005. [CrossRef]

36. Huber, V.; Wagner, C.; Gerten, D.; Adrian, R. To bloom or not to bloom: Contrasting responses of cyanobacteria to recent heat waves explained by critical thresholds of abiotic drivers. Oecologia 2012, 169, 245-256. [CrossRef]

37. Wagner, A.; Volkmann, S.; Dettinger-Klemm, P.M.A. Benthic-pelagic coupling in lake ecosystems: The key role of chironomid pupae as prey of pelagic fish. Ecosphere 2012, 3, 14. [CrossRef]

38. Twining, C.W.; Brenna, J.T.; Lawrence, P.; Shipley, J.R.; Tollefson, T.N.; Winkler, D.W. Omega-3 long-chain polyunsaturated fatty acids support aerial insectivore performance more than food quantity. Proc. Natl. Acad. Sci. USA 2016, 113, 10920-10925. [CrossRef]

39. Kowarik, C.; Martin-Creuzburg, D.; Robinson, C.T. Cross-ecosystem linkages: Transfer of polyunsaturated fatty acids from streams to riparian spiders via emergent insects. Front. Ecol. Evol. 2021, 9, 707570. [CrossRef]

40. Servia, M.J.; Heydorff, M.; Péry, A.R.R.; Garric, J.; Lagadic, L. Sex- and developmental stage-related changes in energy reserves in fourth-instar larvae of the midge Chironomus riparius Meigen (Diptera: Chironomidae): Implications for ecotoxicology testing. Environ. Entomol. 2006, 35, 865-874. [CrossRef] 